\title{
Sexually transmitted diseases including HIV infection in women with Bartholin's gland abscesses
}

\author{
A A Hoosen, C Nteta, J Moodley, A W Sturm
}

\begin{abstract}
Objectives-The aim of this study was to establish the prevalence of sexually transmitted infections including human immunodeficiency virus (HIV) infection in women with Bartholin's gland abscess. Setting-Gynaecology Clinic of King Edward VIII Hospital, a large urban, referral hospital for the province of KwaZulu Natal, serving an underprivileged population.
\end{abstract}

Methods-Thirty consecutive women presenting with unruptured Bartholin's gland abscesses were studied. Prior to surgical drainage, aspirates from the abscess cavity and swab specimens from the vagina and endocervix were collected for microbiological investigations. In addition peripheral venous blood samples were obtained for syphilis and HIV antibody testing.

Results-Antibody to HIV was detected in 9 of the $30(30 \%)$ patients studied. Recognised sexually transmitted pathogens were detected in both aspirates and endocervical specimens: Chlamydia trachomatis was detected in 3 aspirate and 2 endocervical specimens whilst Neisseria gonorrhoeae was cultured in 5 aspirate and 7 endocervical specimens. When comparing microorganisms isolated from HIV antibody positive and negative women, only Bacteroides species yielded a significantly higher growth $(p=0.01)$ in the antibody positive women.

Conclusion-Our findings show that women with Bartholin's gland abscesses have a high prevalence of HIV antibody. Furthermore, this is the only study that demonstrates a role for $C$ trachomatis in the aetiology of Bartholin's gland abscesses. Health workers should be aware of the need for appropriate counselling, and comprehensive treatment of sexually transmitted infections including C trachomatis in women with Bartholin's gland abscesses.

(Genitourin Med 1995;71:155-157)

Keywords: Bartholin's gland; STD; abscess

\section{Introduction}

Abscesses of the Bartholin's glands are frequently seen in patients attending gynaecology outpatient departments. The aetiology of these abscesses is known to be polymicro- bial, although Neisseria gonorrhoeae is still thought to be the initiating organism. ${ }^{1}$ Anaerobes, in particular Bacteroides species are the commonest organisms isolated from such abscesses. ${ }^{1-3}$ This is in keeping with the fact that female genital tract infections commonly involve anaerobic bacteria.

By virtue of the fact that sexually transmitted pathogens are the initiators of Bartholin's gland abscesses, there should be an association with other sexually transmitted microorganisms. Consequently, women with Bartholin's gland abscesses may be prone to HIV infection. The aim of this study was to establish the prevalence of sexually transmitted infections including HIV antibody status in women with Bartholin's gland abscesses.

\section{Patients and methods}

Patients

Thirty consecutive women in whom a clinical diagnosis of unruptured Bartholin's gland abscess was made at the gynaecology outpatient's clinic of King Edward VIII Hospital, $(\mathrm{KEH})$, Durban, were studied. $\mathrm{KEH}$ is a large urban, tertiary hospital serving an indigent Black African population. The hospital serves as a referral centre for the province of KwaZulu Natal which has a catchment population of approximately 8 million. The study was conducted over a three month period, September to December 1993. Informed consent was obtained and all patients were counselled for HIV testing. Women who had received antibiotics in the two weeks prior to admission were excluded from the study. Clinical data with regard to age, parity, marital status, past history of sexually transmitted diseases, sexual history and symptoms on presentation were recorded. All women were managed according to standard practice which included hospital admission and surgical drainage of the abscess by marsupialisation under general anaesthesia. Antibiotics were not prescribed prior to surgical treatment.

\section{Microbiological methods}

The external dimensions of the abscess were measured and recorded. A sterile unlubricated speculum was inserted into the vagina and swab specimens collected from the posterior fornix for the isolation of Trichomonas vaginalis, Candida species and Gardnerella vaginalis. Excess vaginal secretion was removed from the cervical os and endocervical swabs were taken for the detection of chlamydial antigen (direct immunofluorescence, Microtrak-Syva) 
Table 1 Clinical data of all patients: results in means, ranges and percentages

\begin{tabular}{|c|c|c|}
\hline & $\begin{array}{l}\text { HIV positive } \\
n=9\end{array}$ & $\begin{array}{l}\text { HIV negative } \\
n=21\end{array}$ \\
\hline $\begin{array}{l}\text { Age in years } \\
\text { Parity } \\
\text { Marital status }\end{array}$ & $\begin{array}{c}22 \cdot 4(18-31) \\
1 \cdot 0(0-2)\end{array}$ & $\begin{array}{c}26 \cdot 3(16-48) \\
2 \cdot 0(0-9)\end{array}$ \\
\hline $\begin{array}{l}\text { No of single women } \\
\text { No of married women } \\
\text { No with past history of STD }\end{array}$ & $\begin{array}{l}9(100) \\
0(0) \\
5(55)\end{array}$ & $\begin{array}{r}16(77) \\
5(23) \\
13(62)\end{array}$ \\
\hline $\begin{array}{l}\text { No with previous Bartholin's } \\
\text { abscess }\end{array}$ & $2(22)$ & $2(10)$ \\
\hline $\begin{array}{l}\text { partners } \\
\text { Duration of symptoms in days }\end{array}$ & $\begin{array}{l}2 \cdot 6(1-9) \\
2.5\end{array}$ & $\begin{array}{l}2 \cdot 8(1-7) \\
2 \cdot 2\end{array}$ \\
\hline $\begin{array}{l}\text { Number of days since last } \\
\text { sexual activity }\end{array}$ & $10 \cdot 7(3-21)$ & $12 \cdot 7(3-18)$ \\
\hline $\begin{array}{l}\text { Site of Abscess } \\
\text { No on left } \\
\text { No of right }\end{array}$ & $\begin{array}{l}5 \cdot 0(56) \\
4 \cdot 0(44)\end{array}$ & $\begin{array}{l}10 \cdot 0(48) \\
11.0(52)\end{array}$ \\
\hline $\begin{array}{l}\text { Dimensions of all abscesses } \\
\text { in cm }\end{array}$ & $3.6 \times 2.2$ & $3.0 \times 2.2$ \\
\hline
\end{tabular}

( ) indicates range or $\%, S T D=$ sexually transmitted disease, $\mathrm{cm}=$ centimetres

and culture for $N$ gonorrhoeae. Thereafter, the abscess surface was cleansed with alcoholic chlorhexidine solution and allowed to dry. A sterile syringe was used to aspirate the contents of the abscess. All specimens were transported to the laboratory within 30 minutes of collection. The aspirated pus was inoculated onto the following media: human blood agar (HBA) for the isolation of Gardnerella vaginalis: chocolate agar for fastidious aerobic and facultative anaerobic bacteria; modified New York City medium for $N$ gonorrhoeae; MacConkey agar for non-fastidious aerobic organisms; Shepards A7 medium for genital mycoplasmas, amikacin blood agar (10\%) plates for anaerobic bacteria and for the detection of chlamydial antigen (as stated above). All plates were incubated at $35^{\circ} \mathrm{C}$ under appropriate atmospheric conditions and all isolates identified by conventional laboratory methods. Venous blood was collected for determination of white cell count, erythrocyte sedimentation rate (ESR) and the following serological tests: syphilis - rapid plasma reagin ( $R P R$ - Becton Dickinson) and reactive sera titred and confirmed by the Treponema pallidum haemagglutination test (TPHA, Fujirebio); HIV-screening test being an ELISA (Abbott Diagnostics) and all positives confirmed by Western Blot (Diagnostic Biotechnology) and hepatitis B surface antigen by radioimmunoassay. (Ausria-Abbott Diagnostics).

Table 2 Micro-organisms isolated from the abscess aspirate, vagina and endocervix

\begin{tabular}{|c|c|c|c|}
\hline & $\begin{array}{l}H I V \\
\text { positive } \\
n=9\end{array}$ & $\begin{array}{l}\text { HIV } \\
\text { negative } \\
n=21\end{array}$ & Pvalue \\
\hline \multicolumn{4}{|l|}{ Abscess aspirate } \\
\hline Bacteroides species & $5(55 \cdot 5)$ & $2(9 \cdot 5)$ & 0.01 \\
\hline Neisseria gonorrhoeae & $2(22 \cdot 2)$ & $3(14 \cdot 3)$ & 0.62 \\
\hline Peptostreptococcus spp & $1(11 \cdot 1)$ & $0(0.0)$ & 0.30 \\
\hline Propionibacterium spp & $1(11 \cdot 1)$ & $0(0.0)$ & $0 \cdot 30$ \\
\hline Staphylococcus aureus & $0(0.0)$ & $3(14 \cdot 3)$ & 0.53 \\
\hline Mycoplasma hominis & $0(0 \cdot 0)$ & $1(4 \cdot 7)$ & 1.00 \\
\hline $\begin{array}{l}\text { Chlamydia trachomatis } \\
\text { Vagina }\end{array}$ & $2(22 \cdot 2)$ & $1(4 \cdot 7)$ & $0 \cdot 20$ \\
\hline Candida species & $3(33 \cdot 3)$ & $2(9 \cdot 5)$ & 0.14 \\
\hline Trichomonas vaginalis & $2(22 \cdot 2)$ & $3(14 \cdot 3)$ & 0.62 \\
\hline $\begin{array}{l}\text { Gardnerella vaginalis } \\
\text { Endocervix }\end{array}$ & $0(0.0)$ & $4(19 \cdot 0)$ & 0.28 \\
\hline Neisseria gonorrhoeae & $4(44 \cdot 4)$ & $3(14 \cdot 3)$ & $0 \cdot 15$ \\
\hline Chlamydia trachomatis & $1(11 \cdot 1)$ & $1(4 \cdot 7)$ & 0.51 \\
\hline
\end{tabular}

Statistics

The patients were divided into two groups viz those who had antibody to HIV and those who did not demonstrate antibody to HIV. Descriptive statistics were used. The Student's $t$ test was used to compare differences between the groups and a $p$ value of $<0.05$ was regarded as statistically significant.

\section{Results}

The clinical data of all patients are shown in table 1 . Nine patients (30\%) demonstrated antibody to HIV. There was a statistically significant difference in respect to parity between the two groups $(p=0.0004)$. None of the other parameters demonstrated any significant difference. There were a variety of presenting symptoms ranging from pain and swelling in the genital area to vaginal discharge. The commonest presenting feature was a combination of pain and swelling (17 of $30 ; 57 \%)$.

Table 2 shows the micro-organisms isolated from the various sites. Bacteroides species was the only organism more commonly isolated from the HIV antibody positive group (56\% versus $10 \%: p=0.014$ ). $N$ gonorrhoeae was isolated in equivalent numbers from endocervical and abscess aspirates in both groups. $C$ trachomatis was detected in abscesses of three patients, two of whom were HIV antibody positive and in two of these $N$ gonorrhoeae was also cultured from the abscess aspirate.

Serological evidence of syphilis was present in two HIV negative patients ( 2 of $21 ; 9.5 \%$ ). None of the HIV antibody positive patients demonstrated serological evidence of syphilis. Hepatitis B surface antigen was not detected in any patient. There were no significant differences between the groups in respect of mean levels of ESR and white cell count. The average number of days spent in hospital for both groups was 2.4 days. Of the entire group only nine patients $(30 \%)$ returned for follow up on the fifth day after marsupialisation; two of these were HIV antibody positive. All patients had an uneventful recovery.

\section{Discussion}

In developing countries, young women are stated to have the highest incidence of HIV antibody positivity. ${ }^{4}$ The figure quoted for antenatal clinic attenders in Natal (1991) by the National HIV Survey was $2.9 \% .^{5}$ This figure has increased to approximately $8 \%$ in 1993 (unpublished data). Furthermore, in the gynaecology outpatients department at $\mathrm{KEH}$, the prevalence of HIV antibody positivity is $3 \% .^{6}$ These rates, although high are much lower than our finding of $30 \%$ HIV positivity in women with Bartholin's gland abscesses. The reason for this high incidence of HIV antibody positivity in women with Bartholin's gland abscess is not clear. There is evidence to suggest that injury to mucous membranes in the lower genital tract may facilitate transmission of the virus. Naidu et $a l^{7}$ working at the 
Colposcopy Clinic, $\mathrm{KEH}$, found that $5 \%$ of women with dysplasia were HIV antibody positive. It is possible that the extent of mucosal damage in Bartholin's gland abscess is greater than that which occurs with cervical dysplasia. Furthermore, abscesses generally indicate longstanding inflammation and consequently prolonged exposure to viral transmission. It is also possible that because the Bartholin's gland is actively involved in coitus, this may facilitate transmission of the virus. The small number of the study population $(n=30)$ may be a point of criticism, but we could find no other reports in the literature of the association between Bartholin's gland abscess and HIV seropositivity.

The recognised sexually transmitted pathogen associated with Bartholin's gland abscess is $N$ gonorrhoeae. This organism was found in $17 \%$ ( 5 of 30 ) of all aspirates. This finding is in keeping with other reports. ${ }^{28}$ The role of $C$ trachomatis in the aetiology of Bartholin's gland abscesses has not been fully evaluated. A case report ${ }^{9}$ suggests that it has a causal role. Support for this view is provided by Davies $e t$ al ${ }^{10}$ who cultured the organism in 9 of 30 specimens obtained from Bartholin's ducts. Our finding of $C$ trachomatis in 3 aspirates indicates a causal role in Bartholin's gland abscesses.

An interesting finding in our study was the higher prevalence of Bacteroides species isolated from women who were HIV antibody positive than from those who were HIV antibody negative. This difference was significant $(p=0.014)$. We cannot explain this observation and further investigation is required to confirm our findings in HIV positive women.

Syphilis is endemic in the local community. Opai-Tetteh et al ${ }^{11}$ found a prevalence of $11 \%$ in antenatal patients. In our study, the prevalence of syphilis was similar to their findings. None of the HIV antibody positive patients had positive syphilis serology and this may be related to the small sample size.

In our study only 9 of the 30 patients returned for "follow up". This despite counselling by one of the authors (CN). It is well known that continued health care of patients in developing countries is faced with the problems of recalling patients for counselling, education and assessment of any complications. Unpublished data suggest that only $40 \%$ of patients return for the initial medical condition for various reasons.

Our preliminary findings suggest that women with Bartholin's gland abscess have a high prevalence of HIV antibody positivity. It is important for health personnel attending such patients to be aware of our findings and to screen for HIV antibody following appropriate counselling and education. We recommend that a study involving a larger number of patients with long term follow up be implemented to establish the outcome in such individuals.

The authors thank Sandy Moodley for preparation of this manuscript and Coleen Moodley for her diligence in processing the microbiological specimens.

1 Jones HW, Jones GS. Diseases of the vulva. In: Jones HIV III, Wentz AC, Burnett LS, eds. Novak's Textbook of Gynaecology. 10th ed. Baltimore: Williams and Wilkins. 1981:229-33.

2 Brodi I. Aerobic and anaerobic microbiology of Bartholin's abscess surgery. Obstet Gynecol 1989;169:32-4.

3 Lingham M, Hoosen AA, Moodley J, Coetzee K, van den Ende J. The microbial aetiology of Bartholin's abscess and associated sexually transmitted pathogens in black women. $S$ Afr $₹$ Epidemiol Infect 1990;5:11-13.

4 O'Farrell N, Windsor J, Becker P. HIV-1 Infection among heterosexual attenders at a sexually transmitted disease heterosexual attenders at a sexually transmitt
clinic in Durban. $S$ Afr Med $\mathcal{f} 1991 ; 80: 17-20$.

5 Epidemiological comments. Third National HIV Survey of women attending antenatal clinics, South Africa, October/November 1992. 1993;20:35-50.

6 Dhai A, Green-Thompson RW. Syphilis and HIV infection among gynaecology patients at King Edward VII Hospital, Durban. Obstet Gynecol Forum 1993;3:24-6.

7 Naidu S, Hoosen AA, Moodley J, Mayat N, Kharsany ABM. HIV status and sexually transmitted pathogens in women attending colposcopy clinic. $S$ Afr $\mathcal{F}$ Epidemiol Infect 1992;9:24-6.

8 Lee YH, Ronkin JS, Alport S, Daly AK, McCormack WM. Microbiological investigation of Bartholin's gland WM. Microbiological investigation of Bartholin's gland
abscesses and cysts. Am $\mathcal{f}$ Obstet Gynecol 1977;129: abscess

9 Saul HM, Grossman MB. The role of Chlamydia trachomatis in Bartholin's gland abscess. Am $\mathcal{f}$ Obstet Gynecol 1988;158:576-7.

10 Davies JA, Rees E, Hobson D, Kanayiammis P. Isolation of Chlamydia trachomatis from Bartholin's ducts. $B r f$ Venereal Dis 1978;54:409-13.

11 Opai-Tetteh ET, Hoosen AA, Moodley J. Rescreening for syphilis at the time of delivery in areas of high prevalence. $S$ Afr Med $\mathcal{F}$ 1993;83:725-6. 